\title{
Students Designing and Building Satellites: Penn State's LionSat and the University Nanosat Program
}

\author{
Sven G. Bilén, Charles L. Croskey, Robert Melton, David Spencer, \\ Deborah Levin, and Michael M. Micci
}

\author{
College of Engineering \\ The Pennsylvania State University \\ University Park, PA 16802
}

\section{Introduction}

The Local Ionospheric Measurements Satellite (LionSat) mission provides a wealth of learning experiences for the students who are involved in designing, building, and flying Penn State's first student-built satellite [Mistoco et al., 2003]. A key part of LionSat is the educational programming available to students of diverse backgrounds and academic interests. Our educational goal is to prepare students at the undergraduate and graduate levels for productive careers in technical and nontechnical fields relating to space systems and science. The LionSat mission introduces relevant hands-on opportunities to students through design problems, science questions, case studies, research investigations, leadership experiences, organizational issues, etc. LionSat introduces meaningful and realistic project examples into the classroom and laboratory, which enhance student learning.

The LionSat mission was selected as a participant in the University Nanosat-3 (NS-3) program, which is a joint program between the American Institute of Aeronautics and Astronautics (AIAA), the National Aeronautics and Space Administration's Goddard Space Flight Center (NASA GSFC), the Air Force Office of Scientific Research (AFOSR), and the Air Force Research Labs Space Vehicles Directorate (AFRL/VS). The objectives of the NS-3 program are to educate and train the future workforce through a national student satellite design and fabrication competition and to enable small satellite R\&D, payload development, integration, and flight test. Also important to the program is the ability to fly new technologies to validate their operation in a space environment. There are 13 universities participating in NS-3. All universities were provided grants of approx. $\$ 100 \mathrm{k}$ over two years as seed money for their satellite development.

LionSat is a multi-disciplinary space systems project involving several departments of The Pennsylvania State University, including the electrical, aerospace, and mechanical engineering departments. The project also includes students from the College of Science and the College of Education. The Communications and Space Sciences Laboratory (CSSL), located on campus, is serving as the coordination center for the project. The research conducted by the 
CSSL is focused on electromagnetics, atmospheric, and ionospheric properties. As a result, this present effort is well integrated with laboratory efforts to understand the ionosphere. Although LionSat's scientific goals are important, the educational objectives are the driving force for the project. Consequently, student involvement in all aspects and at every level is a priority. This project is designed and managed by students with assistance provided by different faculty members assuming mentoring and advising roles

These satellite design projects equip students with many of the abilities that industry desires in the new engineering graduate, such as ability to address a customer's needs, effective time management, experience with integrated product development/concurrent engineering, effective communication skills, thorough understanding of current design tools, and sense of the total business equation. These projects also provide the student with "hands-on" experience in "real-world" engineering problems that are often not possible through courses alone. In general, for design experiences ABET desires that the design experience should [ABET 2000]:

- include a variety of realistic constraints, such as economic factors, safety, reliability, aesthetics, ethics, and social impact;

- be a meaningful, major engineering design experience that builds upon the fundamental concepts of mathematics, basic sciences, the humanities and social sciences, engineering topics, and communication skills;

- be taught in section sizes that are small enough to allow interaction between teacher and student;

- be an experience that must grow with the student's development; and

- focus the student's attention on professional practice and be drawn from past course work.

Clearly, university nanosatellite projects are excellent design experiences that match up well to the formal educational, rather than just the experiential, aspects of the design experience. This paper will discuss the NS-3 program and the entry being designed and built at Penn State: LionSat. Following both descriptions, we provide an evaluation of the program to date and suggestions for the future.

\section{University Nanosatellite Program Overview}

The NS-3 program has two distinct stages, a two-year competitive phase during which all universities participate by designing and constructing an engineering design unit (EDU) nanosat and participating in various design reviews and activities. [AFRL, 2003] The EDU is to be considered a "protoflight" unit satellite. The first phase culminates in the AIAA Student Satellite Flight Competition, during which one nanosat is selected for flight. Students construct and test the flight unit during the second phase, which ultimately culminates in launch of the nanosat. NS-3 program personnel will assist the winning university with constructing the flight unit and in negotiating the launch vehicle integration and safety process. The university-built nanosat is expected to be flight-ready by September of 2005. An overview of the NS-3 program milestones is given in Table 1. Note that this schedule is fairly aggressive so that students can see multiple phases of a satellite development process during their tenure. 
Table 1 NS-3 program milestones (future dates and locations are tentative)

\begin{tabular}{|l|l|c|}
\hline Milestone & Location & Date \\
\hline $\begin{array}{l}\text { Kickoff and Industry Teaming } \\
\text { Meeting }\end{array}$ & $\begin{array}{l}\text { Space Technology and Applications } \\
\text { International Forum (STAIF 2003), } \\
\text { Albuquerque, NM }\end{array}$ & Feb 03 \\
\hline System Concept Review & Telecon & April 03 \\
\hline $\begin{array}{l}\text { Student Hands-on Training } \\
\text { (SHOT) Workshop }\end{array}$ & University of Colorado at Boulder & July 03 \\
\hline Preliminary Design Review & Small Sat Conference, Logan UT & Aug 03 \\
\hline Satellite Fabrication Class & Air Force Research Lab, Albuquerque NM & Oct 03 \\
\hline Subsystem Design Review & Dulles, VA & Jan 04 \\
\hline SHOT Workshop & University of Colorado at Boulder & June 04 \\
\hline Critical Design Review & Small Sat Conference, Logan, UT & Aug 04 \\
\hline Flight Competition Review & AIAA Aerospace Sciences Meeting, Reno, NV & Jan 05 \\
\hline Phase II Safety Review & Johnson Space Center, Houston, TX & Apr 05 \\
\hline $\begin{array}{l}\text { Nanosat Flight Unit Delivery } \\
\text { to AFRL }\end{array}$ & Air Force Research Lab, Albuquerque NM & Jul 05 \\
\hline $\begin{array}{l}\text { Integrated Testing of Flight } \\
\text { Hardware }\end{array}$ & $\begin{array}{l}\text { Air Force Research Lab, Albuquerque NM or } \\
\text { Goddard Space Flight Center }\end{array}$ & Jul/Aug \\
\hline Phase III Safety Review & Johnson Space Center, Houston, TX & Nov 05 \\
\hline Launch & KSC & Mar 06 \\
\hline
\end{tabular}

Brief descriptions of the several of the milestones listed in Table 1 are presented here. Participation in the events form part of the evaluation criteria for selection (described in more detail in Table 2 below).

The Kickoff Meeting allowed NS-3 program representatives to brief participating universities on the details and goals of the program. In addition, representatives from industry were available at the kickoff to discuss possibilities for teaming. Although some offered donations of hardware, a number also wished to sell their hardware, which was not feasible for most programs since the seed money provided does not allow for "space qualified" cost structures.

The Student Hands-on Training (SHOT) Workshop, which was held twice, is a three-day educational program conducted by the Colorado Space Grant Consortium and the University of Colorado at Boulder. The program gives students an opportunity to design and launch a small experiment on a high altitude balloon, in order to observe the effects of a near space environment on a typical flight experiment.

The AFRL conducted a two-day satellite fabrication class for participating teams at the AFRL in Albuquerque, NM. Class instructors were engineers and technicians from the Aerospace Engineering Facility at AFRL. The class covered such topics as wire harnessing, soldering, mechanical assembly, test, cleanliness, electrostatic discharge, etc. 
Four design reviews took place prior to the Flight Competition Review. These reviews are very similar to what the students would experience as satellite engineers in industry.

The System Concept Review (SCR) was used to introduce each team's design concepts, definition, objectives, feasibility, and estimated results. This review was conducted by telecon, with the universities providing overview slides of their early nanosat design for all universities to review.

The Preliminary Design Review (PDR) was a review of initial designs (subsystems, interfaces, configuration items) relative to the design requirements provided by the NS-3 program. The SDR was an intermediate review whose intent was to ensure that the PDR concept had evolved into a design that meets requirements and that the universities were taking the appropriate management steps to assure successful build and test.

At the Subsystem Design Review (SDR), teams brought with them demonstration subsystem hardware as well as preliminary subsystem drawings and test plans. The subsystem hardware could be in a developmental stage or could be flight hardware.

The Critical Design Review (CDR) was a review of the design at the 90-95\% completeness level. Teams provided design drawings, subsystem assembly procedures, and results of subsystem-level testing. The CDR was the last NS-3 program assessment of the design with regard to maturity, risk, compliance with requirements, etc., prior to protoflight hardware build.

The Flight Competition Review (FCR) was the event at which the flight nanosat was selected. The review was a one-day event in which the competition submittals were evaluated by panel of judges consisting of aerospace industry leaders. The panel had only 25 minutes which each of the 13 nanosatellite to make their evaluations based on several criteria. The nanosats were evaluated in three major categories: student participation, technical relevance, and flyability. Table 2 provides an overview of the scoring structure. Note that all points were awarded at the FCR and were not accumulated during the course of the program.

Table 2 University Nanosat 3 program scoring criteria

\begin{tabular}{|c|c|}
\hline Scoring Criteria & Sub Criteria \\
\hline \multirow[b]{3}{*}{$\begin{array}{l}\text { Student Participation } \\
\text { and Education } \\
\text { ( } 45 \text { points) }\end{array}$} & Educational outreach to students in grades $\mathrm{K}-12$ ( 5 points) \\
\hline & Attendance and participation at program milestones ( 20 points) \\
\hline & $\begin{array}{l}\text { Student involvement ( } 20 \text { points) } \\
\text { - Involvement of students at all levels of the Nanosat program } \\
\text { - Involvement of students from a range of engineering and other } \\
\text { disciplines } \\
\text { - Involvement of students at various education levels (e.g. } \\
\text { undergraduate and graduate) }\end{array}$ \\
\hline $\begin{array}{l}\text { Technical Relevance } \\
\text { (35 points) }\end{array}$ & $\begin{array}{l}\text { Each nanosats' technologies are evaluated on the basis of benefit } \\
\text { and interest to NASA and the Air Force }\end{array}$ \\
\hline $\begin{array}{l}\text { Flyability } \\
\text { (20 points) }\end{array}$ & $\begin{array}{l}\text { Probability of mission success ( } 10 \text { points) } \\
\text { - Ability to successfully complete the proposed on-orbit }\end{array}$ \\
\hline
\end{tabular}




\begin{tabular}{|l|l|}
\hline & experiment(s), including plans to complete and support flight \\
nanosat build and operations \\
- Ability to survive the launch and on-orbit environments \\
- Compliance with the NS-3 program requirements \\
- University implementation of effective plans for Program and \\
Configuration Management \\
- Nanosat EDU operates as planned \\
$\begin{array}{l}\text { Safety (10 points): compliance with NASA safety requirements } \\
\text { (ground and flight), ability to successfully complete the NASA } \\
\text { phased safety review process }\end{array}$ \\
\hline
\end{tabular}

\section{LionSat Program Objectives}

LionSat is designed as a "sciencecraft" with science experiments and bus fully integrated. (Figure 1) LionSat is a spinner that will "roll along" the orbit with the spin axis perpendicular to the orbit plane. It will explore the ram/wake structure of a small spacecraft via plasma probes placed on booms [Surrusco et al., 2004] that will move in and out of the wake as the nanosatellite "rolls" along its orbit (i.e., LionSat's spin axis is perpendicular to the orbital plane). LionSat will obtain ambient measurements of the undisturbed plasma environment and correlate them to the ram/wake measurements. The plasma measurements of the local ambient as well as $\mathrm{ram} /$ wake plasma environments will be made via a novel hybrid plasma probe [Siegel, 2003] that will operate in different modes to investigate a broad range of geophysical conditions that occur on various temporal and spatial scales. The primary engineering goal of LionSat is to flight test a miniature RF ion thruster (MRIT) by increasing the spin-rate of the spacecraft using a pair of MRITs [Mistoco et al., 2004]. Through measuring the increase in spin, the LionSat team will be able to determine thrust levels obtained with the MRIT. LionSat will also employ and test Internet Protocol (IP) communications for uplink and downlink [O'Connor et al., 2004; Surrusco et al., 2003]. An exploded view of LionSat highlighting several spacecraft systems is shown in Figure 2.

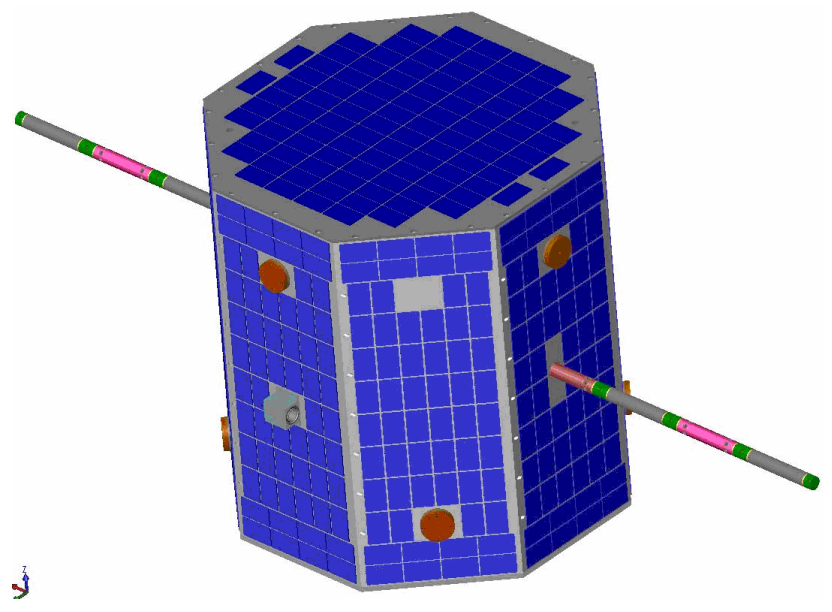

Figure 1 LionSat with booms extended 


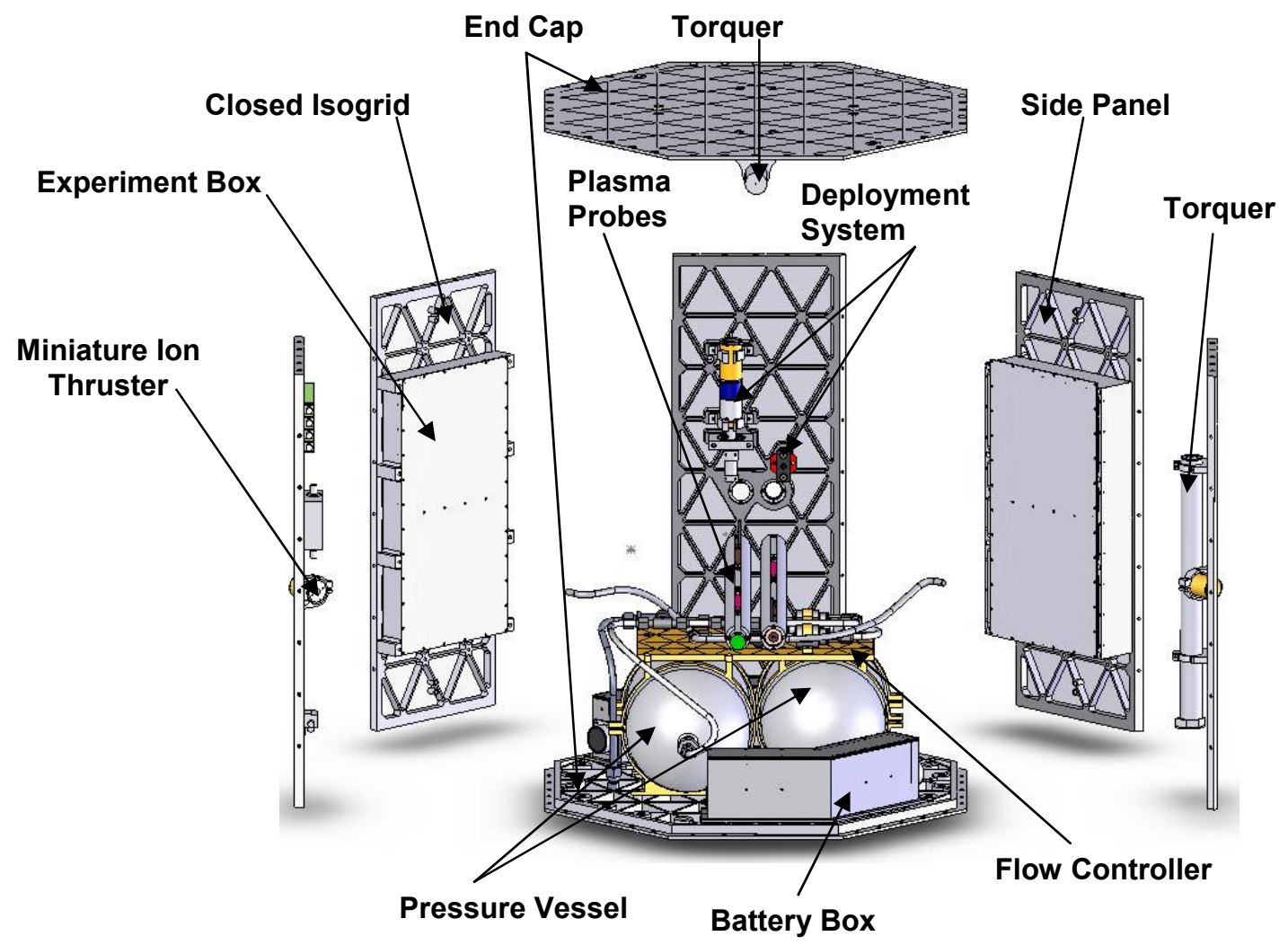

Figure 2 Exploded view of LionSat highlighting several primary systems

The LionSat project introduces relevant hands-on opportunities to students through design problems, case studies, research investigations, leadership experiences, organizational issues, etc. Over 100 students at all educational levels have been involved with LionSat and many hundreds more have been exposed to it through outreach efforts. (Figure 3) The project was managed by the faculty PI with a graduate student project manager funded from the AFOSR award. The graduate student provided continuity from semester to semester as well as over the summer months.

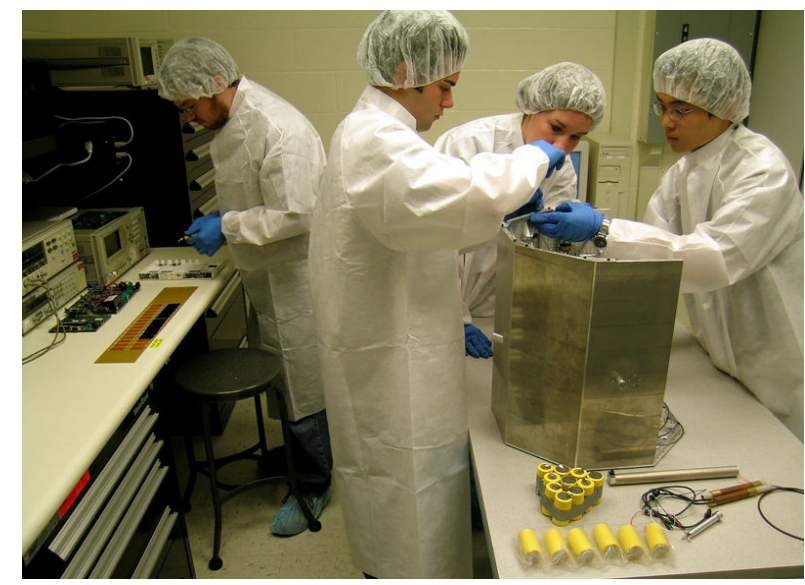

Figure 3 Students begin assembling LionSat in CSSL's cleanroom facility 
Different instructional models to involve students are used on LionSat, based on educational objectives and the students' interests. A particular strength of LionSat is the opportunity for students to grow academically as the project matures, and to develop skills not always evident in the classroom, such as team building, group learning, and mentoring. This "vertically integrated laboratory experience," employed with success in other projects at Penn State [Maughmer et al., 1992; Bieniawski et al., 1994; Kunz and Maughmer, 1996], is highly effective with the LionSat project.

Using a vertical laboratory model when appropriate, the student cohort is mixed in academic maturity. A number of lower-division (first year/sophomore) students have been have been involved, giving them the opportunity to academically grow with the project. Upperdivision (junior/senior) and graduate students provided the academic maturity and leadership to the groups during the initial planning and design phase. An important consideration in working with such groups have been fitting the students' interests and abilities to the tasks and presenting the challenges to motivate and not overwhelm them educationally.

LionSat also provides a wealth of opportunities to educate larger numbers of students in lecture and laboratory courses by transporting the problems encountered on the project into the classroom as case studies. An example of this is the senior capstone design project, intended as a culminating educational experience in which students integrate the theory and practice from previous semesters to develop meaningful designs. At PSU, an NSF-sponsored Learning Factory has been established to facilitate the actual design fabrication process. A total of five capstone projects were sponsored by LionSat via a "subcontractor" model. include:

A number of existing courses were significantly enhanced by the LionSat project. These

Spacecraft Design (AERSP $401 \mathrm{~A} / \mathrm{B}$ ) - In these senior-level capstone design courses, students work in teams to develop conceptual, preliminary, and detailed designs in conjunction with the mission design process. For LionSat, several teams were assigned to develop the spacecraft bus and assist with the analysis and design of the vehicle, payload integration, testing, and launch preparations. Other teams were assigned to assist with the development of the payload operations.

Space Science and Technology (AERSP/STS 055)—This General Education course is for students in nontechnical majors who have an interest in the means and uses of space science and technology. Its ultimate goal is to help prepare students whose careers may eventually impact the direction of space policy, funding of NASA, and other aspects of public support for space research and exploitation. Since the course devotes several weeks to satellite hardware, the LionSat mission has provided new opportunities to inject timely examples of satellite design, measurement concepts and applications, and societal issues regarding public funding of space projects.

Satellite Communications (EE 497F) — Case studies appropriate to LionSat were introduced as part of this course on satellite communication technology. A broad coverage of this topic is provided that includes fundamentals of orbital mechanics, propagation effects, descriptions of Earth and space systems employed by satellite links, the analog and digital 
signals carried by satellites, interference peculiar to satellite networks, multiple access methods, and descriptions of selected satellite services. LionSat personnel have presented several lectures and provided projects for EE 497F.

Independent Studies of Antenna Design (EE 496) — Students have been involved in the design, fabrication, and testing of antennas for different practical applications. Computer modeling has been instrumental to this work. Both undergraduates and graduates have assisted with antenna design projects. As part of LionSat, students investigated various proposed antenna designs (GPS, transmitting, and receiving) and were involved in the actual construction of the satellite antennas and their performance measurement and validation in CSSL's anechoic chamber.

There was considerable graduate and undergraduate student interest in more narrowly focused studies appropriate for theses and scholarly papers. While the educational objectives of LionSat are focused on collaborative learning experiences, such activities as independent research projects were also supported, and we encouraged these students to get involved on a group basis. Several bachelors and masters theses have been developed on work done for LionSat.

The LionSat faculty advisors have mentored a large number of students. A number of the faculty and staff on campus have been willing and interested to share their expertise with students on a voluntary consulting basis. In fact, many of these individuals have funding support from NASA, and they are very inclined to assist students in a project of this kind. Such mentoring opportunities outside the classroom provide a very meaningful form of learning. The excitement from these interactions is impressionable and contagious.

Communication between the members of the LionSat team is accomplished through a combination of direct meetings and Internet-based conferences. We believe that peer-to-peer mentoring provides important support for the new members of the design teams. For LionSat, we encouraged these informal exchanges of ideas by providing a $700 \mathrm{sq}$. $\mathrm{ft}$. laboratory in the CSSL of the Department of Electrical Engineering for use as a design studio. This laboratory space is located adjacent to both the Class 10,000 clean room and the offices of the PI and several Co-Is, so that informal faculty-student mentoring could also easily occur.

\section{Program Assessment and Summary}

One of the stated goals of the Nanosat Program is to develop a cohort of students familiar with and interested in satellite design for employment in related areas of in industry, government, and academia. One of the questions posed by the NS-3 program directors was whether or not the students who are involved in the University Nanosat Program are more likely to enter the aerospace engineering field upon graduation than non-participants. There is indeed a fair bit of anecdotal evidence that this type of space systems project is a strong motivator of students to enter space-related fields. It was not possible for us to track this exactly, so the best we can do is qualitative (the NS-3 program did not require us to track this from the beginning; however, it would be highly desirable for the follow-on NS programs to implement some type of tracking matric). Since LionSat has heavy involvement from Aerospace and Electrical Engineering, there are a number of students from Aerospace who have already accepted jobs with aerospace 
companies, which is to be expected. However, we have seen a number of students, primarily in EE, who had not previously considered an aerospace career who now are looking into working for aerospace companies after working on LionSat as part of project-based courses (note that some self select into the project, others are assigned). We have even had one CivE student decide to go to grad school in Aerospace. Hence, anecdotal evidence at Penn State indicates exposure to this program makes students more likely to consider aerospace careers.

One of the interesting aspects of the University Nanosatellite program is its development of a large number of students who are exposed to satellite development as a career. NS-3 follows two previous University Nanosat programs. While this is one of the program's strengths, it also generates interesting challenges. For example, while the program mapped the major design gates well (i.e., SCR, PDR, CDR), the reviews are necessarily superficial because of the short time (generally all 13 are reviewed in a single day) and the large number of different missions and subsystems provided by the university teams. The program has provided some standard parts (e.g., batteries and the "LightBand" deployment ring), but most other subsystems have been developed more or less independently by each university. The creation of a Nanosat community, while one of the stated goals, was not fully realized since the teams were also competitors at one level.

Another major difficulty with program's structure is that the Flight Competition Review comes after two years of effort, which is an extremely long time to wait for a downselect. It is understood that this was by design in the program since the sponsors wanted as many students to be exposed to satellite development as possible, but it provided for a number of difficulties. First and foremost is how to keep students motivated for such a long time when launch is not guaranteed. Second has to due with leveraging the "seed funding" provided by AFOSR into additional resources. We were told by many companies seeking to get their hardware flown that they would not commit to providing hardware and resources until we are selected, yet we need the hardware and resources to be selected-providing a Catch-22 situation. A downselect to a few universities earlier in the program (perhaps after a year), each guaranteed launch (similar to NS-2), would rectify many of these issues. Once selected, the teams would be more likely to share resources, ideas, and designs since they are no longer competitors.

There are a number of lessons learned regarding the aerospace capstone class: Because this two-course sequence follows a plan of conceptual, preliminary, then detailed design, the injection of another project (i.e., LionSat) that was already underway created some unique opportunities and challenges. Students who had some previous design experience could chose to work on LionSat and thereby greatly enhance their experience with detailed design and issues of subsystem integration. Assessing their performance required the use of different and more flexible criteria, in part because their progress depended upon activity by students not enrolled in the course (and who were themselves subject to other requirements and different class-meeting schedules). In retrospect, a special-topics course for aerospace students working on LionSat would have eased this difficulty, particularly with regard to the scheduling of meetings and interchange of information.

One of the major issues surrounding satellite development, even at educational institutions, has to due with observing ITAR (International Trafficking in Arms Regulations). Observing these regulations primarily meant that students who are citizens of certain countries 
(generally those not a member of NATO) could not work on the project. This is particularly difficult with respect to graduate students who are often foreign.

The need for this type of student satellite development program exists and agencies and industry should work to provide more opportunities. The University Nanosatellite Program sponsors are to be commended for finding a way to provide a program. Unfortunately, recent years have seen NASA halt its successful Get Away Special program, as well as its UNEX program - two programs that offered student satellite experience. As aerospace educators, we should seek to work with agencies to develop national funded programs that can provide meaningful learning opportunities through students building satellites.

\section{References}

ABET Engineering Criteria 2000, http://www.abet.org/criteria.html, 2000.

AFRL Internal Cargo Unit User’s Guide University Nanosat-3 Program, March 2003.

Bieniawski, S., D.W. Jensen, E.C. Smith, and M.D. Maughmer, "Evolution of a vertically integrated aerospace vehicle design and fabrication course," Proc. of the 1994 ASEE Annual Conference, Edmonton, Alberta, Canada, June 26-29, 1994.

Cipollo, P., * B.S. Surrusco, ** and S.G. Bilén, “An electrically actuated pin-puller for space application using nickel-titanium memory alloy," the 18th Annual, AIAA/Utah State University Conference on Small Satellites, 9-12 August 2004.

Kunz, P.J., and M.D. Maughmer, "The PSU sailplane project," 1996 World Aviation Congress, Los Angeles, CA, Oct. 21-24, 1996.

Maughmer, M.D., and D.W. Jensen, "Enhancing the aerospace educational experience with a multi-year sailplane design project," Proc. of the 1992 ASEE Annual Conference, Toledo, OH, June 21-25, 1992.

Mistoco, V.F.M., ** S.G. Bilén, and M.M. Micci, "Development and chamber testing of a miniature radio-frequency ion thruster for microspacecraft," 40th AIAA/ASME/ASEE Joint Propulsion Conference, Ft. Lauderdale, FL, 11-14 July 2004.

Mistoco, V.F., R.D. Siegel, ** B.S. Surrusco, * E. Medoza,* and S.G. Bilén, "Design of the Local Ionospheric Measurements Satellite," 17th Annual, AIAA/Utah State University Conference on Small Satellites, 11-14 August 2003.

O’Connor, N.F., * B.S. Surrusco, ** S.G. Bilén, and C.L. Croskey, "Software-Defined Radio Ground Station for Internet-Protocol Communications to a Low Earth Orbit Nanosatellite," NASA Fourth Space Internet Workshop, Hanover, MD, 7-9 June 2004.

Siegel, R.D., IV,** Design of a Hybrid Plasma Probe System, M.S. Thesis, Electrical Engineering Dept., Penn State Univ., University Park, PA, May 2004.

Surrusco, B., ${ }^{*}$ R.D. Siegel, ${ }^{* *}$ P.M. Sorber, ${ }^{*}$ D.V. Morr, ${ }^{*}$ N.F. O’Connor, ${ }^{*}$ C.L. Croskey, S.G. Bilén, and J.A. Soloff, "Mission planning for employing internet protocol (IP) communications on the Local Ionospheric Measurements Satellite (LionSat)," NASA Third Space Internet Workshop, Cleveland, OH, 4-6 June 2003.

** Graduate Student, * Undergraduate Student

\section{Acknowledgments}

LionSat sponsors include: Aeroflex Corporation, Air Force Office of Scientific Research, Air Force Research Laboratory Space Vehicles Directorate, Boeing, C\&R Technologies, Lockheed-Martin, National Aeronautics and Space Administration (GSFC), Penn State Aerospace Engineering Department, Penn State College of Engineering, Penn State Electrical 
Engineering Department, American Institute of Aeronautics and Astronautics, and Pennsylvania Space Grant Consortium.

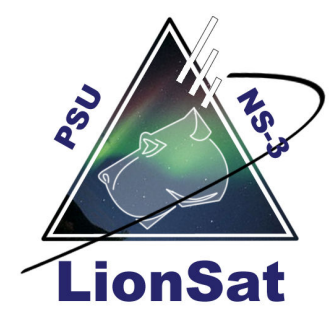

SVEN G. BILÉN (BS Penn State, MSE and PhD Univ. of Michigan) is an Assistant Professor of Engineering Design and Electrical Engineering at Penn State. His educational research interests include developing techniques for enhancing engineering design education and systems engineering. In addition to LionSat, he is faculty advisor for a number of student design projects, including the Flyin' Lions and Get Away Special payloads teams. He is member of IEEE, AIAA, AGU, ASEE, URSI, and Sigma Xi.

CHARLES L. CROSKEY (BSEE, MSEE, and Ph.D. Penn State) is a Professor of Electrical Engineering at Penn State University. His educational interests include the engineering design process and bringing technology to the classroom. At Penn State, he most often teaches courses in electronics and laboratory techniques. He is also a Schreyer Honors College advisor and a member of IEEE, AGU, and ASEE.

ROBERT MELTON (BS Wake Forest Univ., MS and PhD Univ. of Virginia) is a Professor of Aerospace Engineering at Penn State. His educational research interests include development of peer-evaluation instruments for team-based design projects and improving collaborative learning in large classes. He is a Fellow of the AAS, an associate fellow of AIAA, and a member of ASEE and Sigma Pi Sigma.

DAVID SPENCER (BS Univ. of Kentucky, M.S.A.A. Purdue, PhD Univ. of Colorado) is an Assistant Professor of Aerospace Engineering at Penn State. His educational and research interests include spacecraft dynamics and controls, spacecraft design, and space systems engineering. He is the faculty advisor for the Penn State Mars Society and the Aerospace Engineering Graduate Student Association. He is an associate fellow of AIAA, a senior member of AAS, and a member of ASME, ASEE, Pi Tau Sigma, and Tau Beta Pi.

DEBORAH LEVIN (BS SUNY at Stony Brook, PhD Cal Tech) is an Associate Professor of Aerospace Engineering at Penn State.

MICHAEL M. MICCI (BS Univ. of Illinois at Urbana-Champaign, MS Univ. Illinois at Urbana-Champaign, MA Princeton, PhD Princeton) is Professor of Aerospace Engineering at Penn State. 